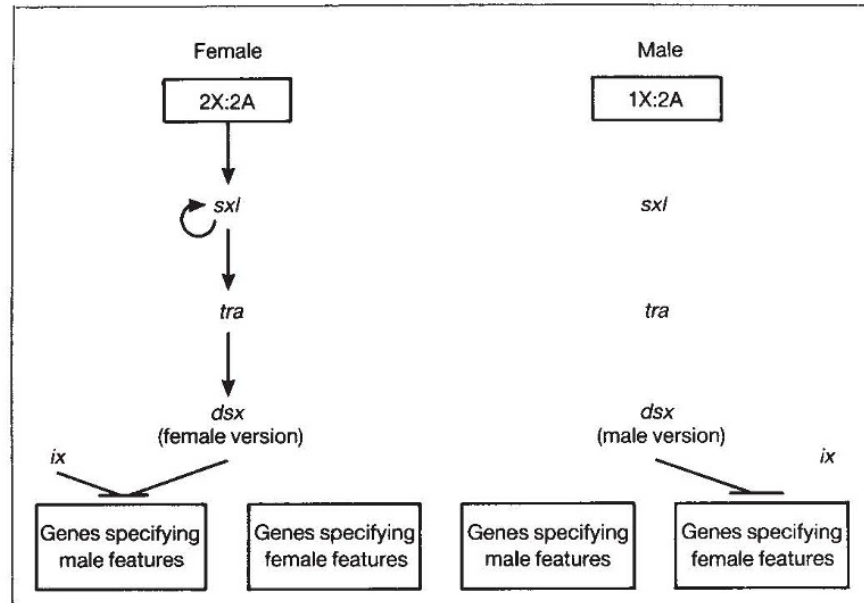

Fig. 3 Sex determination in Drosophila. In fruitflies with two X chromosomes, $s x l$ is activated and activates itself and tra which generate the female version of $d s x$ which, with intersex (ix), suppresses the expression of those genes that determine the male characteristics. In fruitflies with one $\mathrm{X}$ chromosome, $s x l$ is inactive, tra is not activated and the male form of $d s x$ is produced by default. The male variant of $d s x$ suppresses the genes determining female characteristics.

exon containing a stop codon. Because mutations in $s x l$ or tra cause aberrant patterns of splicing in tra and $d s x$, they are presumed to encode components of the RNA processing machinery critical for determining exon usage; and the characterization of their products may converge with the output from mammalian biochemistry in much the way that seems already to be happening in yeast.

\section{Evolutionary intermediates}

It is tempting to reflect that the evolution of sex seems easier to understand if divergence from a (purely hypothetical) hermaphrodite state could be achieved by the combination of an adventitious stop codon with some modification to a component of the splicing apparatus. The flexibility argument for retaining introns moreover gets a further filip from trypanosomes and from nematodes, both of which seem to have evolved the same strategy for economizing on exons by using the same one to encode the $5^{\prime}$ leader sequence of a number of different genes through splicing the $5^{\prime}$ transcript to the rest of the pre-mRNA in trans ${ }^{13.14}$.

Trans-splicing of artificial constructs in a mammalian system in vitro is very inefficient in the absence of any significant complementarity between the introns undergoing the reaction (see ref. 4). There is no such sequence complementarity between the intron portions of the spliced leader transcripts and those of the RNAs to which they become joined; instead, each $5^{\prime}$ leader sequence seems to function as an snRNA.

James Bruzik in Joan Steitz's laboratory at Yale University reported that in a comparison of six species of trypanosomes (or related protozoans) and the nematode Caenorhabditis elegans, similar secondary structures can be derived for all the spliced leader transcripts despite the absence of primary sequence similarity, and these structures include one loop that seems to mimic the $5^{\prime}$ splice site-Ul snRNA interaction. Moreover, the spliced leader transcripts when added to a mammalian splicing extract can be precipitated with antibodies against the $\mathrm{Sm}$ antigen, a protein (or proteins) diagnostic of snRNPs.

Jeffrey Thomas from Tom Blumenthal's laboratory at Indiana University reported at the same time that nematode leader sequences share with snRNPs not only their characteristic relationship with the Sm antigen ${ }^{16.17}$ but also their trimethylguanine cap. The cap is inappropriate however for the mature RNA; and indeed Thomas and colleagues have shown that it is removed or modified in the course of maturation ${ }^{17}$. This, they argue, is perhaps the strongest existing evidence for the snRNA character of the leader since the additional processing step is very difficult to explain unless the trimethylguanine cap is important for trans-splicing.

This and some direct evidence from David Hirsh's laboratory ${ }^{1 x}$ for the existence of branched intermediates of the form shown in column 3 of Fig. 1 startlingly vindicates Sharp's speculation that the solution to the efficiency problem in trans-splicing might be just such a built-in snRNP; and makes the idea of snRNAs as the escaped descendants of self-splicing group 2 introns virtually irresistible.

Gilbert. W Cold Spring Harbor Symu quant Biol 52 901-905 (1987).

Sharp. P. Cell 42, 397-400(1985)

3. Zaug, A.J., Grabowski, P.J. \& Cech, T.R. Nature 301, $578-583(1983)$

4. Sharp. P. Cell 50, 147-148 (1987).

5. Parker, R. Siliciano. P.G. \& Guthric. C. Cell 49, 229-239 (1987)

6. Ioel A.H. \& Ares, M. Jr Nature 334, 450-453 (1988)

7. Ruskin. B.. Zamore. P.D. \& Green. M. R. Cell 52, 2017-219 (1988)

8. McKeown, M., Betote. J.M. \& Baker, B.S. Cell 48, 489 499 (1987).

9. Boggs, R.T. Gregor, P.. Idriss, S., Belote, J.M. \& McKeown, M. Cell 50, 739-747 (1987)

10. Nagoshi. R.N., McKeown. M.. Burtis, K.B.. Belote. B.M \& Baker, B.S. Cell 50, 739-749 (1987).

11. Maine, E.M.. Salz, H.K., Schedl. P. \& Cline, T.W. Cold Spring Harhor Symp. quant. Biol. 50, 595-604 (1985)

12. Baker, B.S. \& Wolfner, M.F. Genes Dev. 2, 477-489(1988).

3. Van der Ploeg, L.H.T. el al. Nucleic Acids Res. 10, 593 $619(1982)$

14. Krause, M. \& Hirsh. D. Cell 49, 753-761 (1987)

15. Bruzik. J. P.. Van Doren. K.. Hirsh. D. \& Steitz, J.A. Nature (in the press)

16. Van Doren, K. \& Hirsh, D. Nature (in the press)

17. Thomas, J.. Conrad, R. C. \& Blumenthal. T. Cell 54. 533 $539(1988)$.

8. Bektesh, S. \& Hirsh. D. Nucleic Acids Res. (in the press).

Miranda Robertson is Biology Editor of Nature.
Daedalus

\section{Franklin flies again}

ONE of the annoying features of temperate weather, especially during a drought, is that most clouds fail to deposit rain. Many experiments with cloud seeding have been tried; Daedalus now proposes a new one. He recalls the classic (and highly dangerous) experiment conducted by Benjamin Franklin: flying a kite in a thunderstorm to conduct atmospheric electricity down the kite-string. Daedalus wants to try it in reverse. By pumping electric charge $u p$ the string, he hopes to trigger a thunderstorm.

A moist atmosphere is often potentially unstable. Once a parcel of warm moist air begins to rise, its water vapour condenses to cloud droplets; the resulting release of latent heat lifts the air further still, drawing in more moist air from the same stratum and triggering a general convective turnover. If the condensing cloud droplets could coalesce they would fall as rain.

So DREADCO's meteorologists are flying a captive balloon on a copper cable among suitable summery clouds. The balloon is equipped with many sharp corona-discharge points, and can be charged up from a big Wimshurst machine on the ground. By cranking the Wimshurst machine at the right moment, a sizeable electric charge can be injected as corona ions into a chosen cloud. Several things can then happen. The ions may nucleate droplet condensation by the cloud-chamber effect, thickening the cloud and releasing latent heat of condensation. If the cloud is below freezing-point, ice crystals may be nucleated instead: these rapidly condense water from a cloud and aggregate it into rain. Even without nucleation, charge injected into a parcel of air will expand it by self-repulsion, thus making it rise. Either way, says Daedalus, a convective instability should be initiated. A cloud charged by his Wimshurst balloon should rapidly develop into a rainstorm. More dramatic still, the generous initial charge on the cloud should be amplified up by the usual atmospheric electrical processes, giving a thunderstorm.

A cloud seeded by DREADCO's 'electric rainer' will release its deluge some while after being triggered, and some distance down-wind. Experience will be needed to judge the best site and timing to soak a given target; but customers should then rush to use the service. Farmers will discharge promising clouds onto their parched crops while police discourage troublesome marches and demonstrations. Sponsors of expensive sports fixtures will pre-emptively drain threatening cloud formations before they reach the sportsground. And unscrupulous evangelists may call thunder and lightning dramatically down from the heavens in support of their claims to higher authority.
David Jones 